\title{
Simultaneous biogas upgrading and biochemicals production using anaerobic bacterial mixed cultures
}

Omar, Basma; Abou-Shanab, Reda; El-Gammal, Maie; Fotidis, loannis; Kougias, Panagiotis; Zhang, Yifeng; Angelidaki, Irini

Published in:

Water Research

Link to article, DOI:

10.1016/j.watres.2018.05.049

Publication date:

2018

Document Version

Peer reviewed version

Link back to DTU Orbit

Citation (APA):

Omar, B., Abou-Shanab, R., El-Gammal, M., Fotidis, I., Kougias, P., Zhang, Y., \& Angelidaki, I. (2018).

Simultaneous biogas upgrading and biochemicals production using anaerobic bacterial mixed cultures. Water Research, 142, 86-95. https://doi.org/10.1016/j.watres.2018.05.049

\section{General rights}

Copyright and moral rights for the publications made accessible in the public portal are retained by the authors and/or other copyright owners and it is a condition of accessing publications that users recognise and abide by the legal requirements associated with these rights.

- Users may download and print one copy of any publication from the public portal for the purpose of private study or research.

- You may not further distribute the material or use it for any profit-making activity or commercial gain

- You may freely distribute the URL identifying the publication in the public portal 


\section{Accepted Manuscript}

Simultaneous biogas upgrading and biochemicals production using anaerobic bacterial mixed cultures

Basma Omar, Reda Abou-Shanab, Maie El-Gammal, loannis A. Fotidis, Panagiotis G. Kougias, Yifeng Zhang, Irini Angelidaki

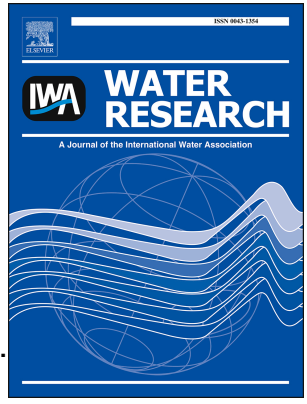

PII:

S0043-1354(18)30421-4

DOI:

10.1016/j.watres.2018.05.049

Reference: WR 13814

To appear in: Water Research

Received Date: 5 February 2018

Revised Date: 7 May 2018

Accepted Date: 28 May 2018

Please cite this article as: Omar, B., Abou-Shanab, R., El-Gammal, M., Fotidis, I.A., Kougias, P.G., Zhang, Y., Angelidaki, I., Simultaneous biogas upgrading and biochemicals production using anaerobic bacterial mixed cultures, Water Research (2018), doi: 10.1016/j.watres.2018.05.049.

This is a PDF file of an unedited manuscript that has been accepted for publication. As a service to our customers we are providing this early version of the manuscript. The manuscript will undergo copyediting, typesetting, and review of the resulting proof before it is published in its final form. Please note that during the production process errors may be discovered which could affect the content, and all legal disclaimers that apply to the journal pertain. 


\section{Simultaneous biogas upgrading and biochemicals production using}

\section{2 anaerobic bacterial mixed cultures}

4 Basma Omar ${ }^{\text {a, b }}$, Reda Abou-Shanab ${ }^{\mathrm{c}}$, Maie El-Gammal ${ }^{\mathrm{b}}$, Ioannis A. Fotidis ${ }^{\mathrm{a}}$, Panagiotis G.

5 Kougias $^{\mathrm{a}}$, Yifeng Zhang ${ }^{\mathrm{a},}$, , Irini Angelidaki ${ }^{\mathrm{a}}$

6

${ }^{a}$ Department of Environmental Engineering, Building 113, Technical University of Denmark, DK$8 \quad 2800$ Lyngby, Denmark

9

$10{ }^{\mathrm{b}}$ Department of Environmental Sciences, Faculty of Science, Damietta University, 34517 Damietta, 11 Egypt

12

$13{ }^{\mathrm{c}}$ Department of Environmental Biotechnology, City of Scientific Research and Technology

14 Applications, Alexandria, 21934, Egypt

15

$16 *$ Corresponding Author: Yifeng Zhang, Department of Environmental Engineering, Technical

17 University of Denmark, DK-2800 Kgs. Lyngby, Denmark, Phone: (+45) 45251410; Fax: (+45)

18 45933850; e-mail: yifz@env.dtu.dk 
19 Abstract

20 A novel biological process to upgrade biogas was developed and optimised during the current

21 study. In this process, $\mathrm{CO}_{2}$ in the biogas and externally provided $\mathrm{H}_{2}$ were fermented under mesophilic conditions to volatile fatty acids (VFAs), which are building blocks of higher-value biofuels. Meanwhile, the biogas was upgraded to biomethane $\left(\mathrm{CH}_{4}>95 \%\right)$, which can be used as a vehicle fuel or injected into the natural gas grid. To establish an efficient fermentative microbial platform, a thermal (at two different temperatures of $70^{\circ} \mathrm{C}$ and $90^{\circ} \mathrm{C}$ ) and a chemical pretreatment method using 2-bromoethanesulfonate were investigated initially to inhibit methanogenesis and enrich the acetogenic bacterial inoculum. Subsequently, the effect of different $\mathrm{H}_{2}: \mathrm{CO}_{2}$ ratios on the efficiency of biogas upgrading and production of VFAs were further explored. The composition of the microbial community under different treatment methods and gas ratios has also been unravelled using 16S rRNA analysis. The chemical treatment of the inoculum had successfully blocked the activity of methanogens and enhanced the VFAs production, especially acetate. The chemical treatment led to a significantly better acetate production (291 mg HAc/L) compared to the thermal treatment. Based upon 16S rRNA gene sequencing, it was found that $\mathrm{H}_{2}$-utilizing methanogens were the dominant species in the thermally treated inoculum, while a significantly lower abundance of methanogens was observed in the chemically treated inoculum. The highest biogas content ( $96 \%$ $(\mathrm{v} / \mathrm{v}))$ and acetate production were achieved for $2 \mathrm{H}_{2}: 1 \mathrm{CO}_{2}$ ratio (v/v), with Acetoanaerobium noterae, as the dominant homoacetogenic hydrogen scavenger. Results from the present study can pave the way towards more development with respect to microorganisms and conditions for high efficient VFAs production and biogas upgrading.

40 Keywords: Biogas upgrading; Acetogens; Biomethane; $\mathrm{CO}_{2}$ mitigation; Gas fermentation; $16 \mathrm{~S}$ rRNA genes 


\section{Introduction}

Anaerobic digestion of organic wastes has gained considerable attention as a promising technology for bioenergy production and environmental pollution control. Biogas produced from the anaerobic digestion process consists mainly of $\mathrm{CH}_{4}\left(40-75 \%\right.$, v/v) and $\mathrm{CO}_{2}(25-60 \%$, v/v) with several trace compounds depending on the organic source (Rotunno et al., 2017). The low $\mathrm{CH}_{4}$ content of biogas limits its application to heating and electricity production (Leonzio, 2016). In order to increase the application possibilities, biogas can be upgraded to more than $95 \%(\mathrm{v} / \mathrm{v}) \mathrm{CH}_{4}$ (biomethane) by removing $\mathrm{CO}_{2}$ and increasing the methane content (Micale, 2015). Biogas upgrading increases the heating value and relative density of biogas. The upgraded biogas can be used as vehicle fuel or injected to the natural gas grid.

To date, biogas upgrading is performed in approximately 280 biogas plants around the globe, using several different technologies (Kougias et al., 2017). The most common established technologies are based on: adsorption (pressure swing adsorption), absorption (pressurized water wash, physical or chemical absorption), membranes (high pressure, low pressure), and cryogenic separation (Sun et al., 2015). The costs of these technologies are relatively high as they require either high pressure, or addition of chemicals, or membranes (Luo and Angelidaki, 2013; Yan et al., 2016). Moreover, $\mathrm{CH}_{4}$ loss during separation of $\mathrm{CO}_{2}$ from biogas by these technologies is another significant limitation (Luo and Angelidaki, 2012). Therefore, there is room for the development of new technologies that will improve the overall biogas upgrade efficiency and, at the same time, will reduce the investment, operation and maintenance costs.

Biological biogas upgrading is a promising technology with high efficiency and low investment and operational costs (Kao et al., 2012; Xu et al., 2014; Bassani et al., 2016). Different biological systems have been used for biogas upgrading, such as microalgae to capture $\mathrm{CO}_{2}$ from biogas (Sun et al., 2015), or hydrogenotrophic methanogenic archaea to convert in-situ or ex-situ $\mathrm{CO}_{2}$ and $\mathrm{H}_{2}$ to 
$\mathrm{CH}_{4}$ (Rittmann, 2015). However, the selection of appropriate microorganisms for efficient and economical biogas upgrading has still not been explored.

$$
\text { Recently, acetogenic bacteria have attracted great interest in the bioenergy technology due to }
$$
their ability to efficiently fix $\mathrm{C} 1$ compounds (including $\mathrm{CO}_{2}$ ) using $\mathrm{H}_{2}$ as an electron donor via the acetyl-CoA pathway and produce valuable chemicals (e.g. organic acids) that can be used in the chemical industry (Fernández-naveira et al., 2017). These bacteria with 23 different genera and over 100 species identified up to date, are strictly anaerobic and produce billions of tons of acetate globally each year as their major fermentation product (Groher and Weuster-Botz, 2016). Acetogens can inhabit very diverse ecosystems ranging from different soils to termite hindgut, with wide variations in temperature, $\mathrm{pH}$, and salinity (Vandecasteele, 2016). Several acetogenic pure cultures especially within the Clostridium spp. have been used for biochemical production (Fernández-naveira et al., 2017). Recently, mixed culture fermentation has gained more attention due to several advantages compared to the pure culture; such as process robustness during continuous processes and no need for sterile conditions (Redl et al., 2017). Taking all together, $\mathrm{CO}_{2}$ from biogas could be converted to building blocks of higher value biofuels (e.g., VFAs) instead of $\mathrm{CH}_{4}$, by using mixed culture acetogenic consortia. However, the ability of the acetogenic bacteria to simultaneously upgrade biogas and produce biochemicals has never been assessed. point sources, including coal gasification, petroleum refinery, petrochemical plants, and soda manufacture (Luo and Angelidaki, 2012). However, to make the whole process economically and environmentally sustainable, hydrogen should be produced from renewable resources. One of the most promising renewable sources of $\mathrm{H}_{2}$ is the electrolysis of water using surplus electricity generated by wind or solar energy (Kougias et al., 2017). However, $\mathrm{H}_{2}$ is not yet a competitive transportation fuel due to high transportation cost, development of country scale infrastructure and 
90 low volumetric energy content (Ramachandriya et al., 2013). On the contrary, utilization of $\mathrm{H}_{2}$

91 produced from renewable resources for biogas upgrading has several advantages, such as usage of

92 the existing infrastructure of biogas plants and using the energy of hydrogen for chemicals

93 production (Luo et al., 2012).

94 The present study aimed to develop a novel bioprocess that combines renewable electricity

95 utilization and $\mathrm{CO}_{2}$ fixation by acetogenic bacteria, to efficiently upgrade biogas and produce

96 biochemicals. Therefore, a series of experiments were performed to identify the best pre-treatment

97 method that inactivates the methanogenic archaea in the inoculum and enriches the acetogenic

98 bacteria. Subsequently, the optimum $\mathrm{H}_{2}: \mathrm{CO}_{2}$ gas ratio for maximum biogas upgrading efficiency

99 and production of chemicals was assessed. In addition, 16S rRNA analysis of the microbial

100 community was conducted to better understand the process from the microbiological point of view.

1012 Materials and methods

\subsection{Inoculum}

Mesophilic digested sewage sludge (wastewater treatment plant, Lundtofte, Denmark) was used as inoculum in this study. Inoculum was sieved through a $2 \mathrm{~mm}$ net after collection to remove large particles and then was kept three days in the incubator at $37 \pm 1^{\circ} \mathrm{C}$ before starting the batch experiments. The basic characteristics of the inoculum are presented in Table 1.

\subsection{Experimental setup}

The mixed culture was maintained under strictly anaerobic conditions in a basic anaerobic medium (BA-medium) (Angelidaki et al., 1990), with the exception that all the carbon source (e.g.

$110 \mathrm{NaHCO}_{3}$ ) were omitted to minimize the interference of carbon compounds during the fermentation

111 process. All the experiments were performed in $540 \mathrm{~mL}$ serum bottles with $100 \mathrm{~mL}$ working

112 volume. The bottles were sealed with butyl rubber stoppers and aluminium crimps and then 
113 autoclaved at $121^{\circ} \mathrm{C}$ and 15 psi for $20 \mathrm{~min}$. The filter sterilized vitamin solution using micro syringe

114 filter $(0.2 \mu \mathrm{m})$ was added to the bottles after cooling at room temperature. Before inoculation,

115 sodium sulphide was added to the serum bottles (final concentration of $0.025 \% \mathrm{w} / \mathrm{v}$ ) to ensure

116 anaerobic conditions. The mixed culture was used as a starting inoculum at the rate of $10 \%$ of the

117 working volume. The initial $\mathrm{pH}$ of the medium was adjusted at $6.0 \pm 0.1$ with $2 \mathrm{~N} \mathrm{KOH}$ and $2 \mathrm{~N}$

$118 \mathrm{HCl}$ solutions. All bottles were incubated horizontally (to maximize gas-liquid transfer) at $37 \pm 1^{\circ} \mathrm{C}$

119 with a constant agitation of $150 \mathrm{rpm}$ in an orbital shaker (IKA ${ }^{\circledR} \mathrm{KS} 4000 \mathrm{i}$ control).

\subsubsection{Pre-treatment methods for inactivation of methanogens}

The potential methanogenesis inactivation methods were a crucial step of the current study. Therefore, batch experiments were performed to elucidate the efficiency of different methanogens inactivation methods (thermal and chemical treatments) and promotion of acetate production under mesophilic conditions. For the heating pre-treatment, two different temperatures $\left(70^{\circ} \mathrm{C}\right.$ and $\left.90^{\circ} \mathrm{C}\right)$ were tested. In both temperatures, the inoculum was heat shocked for $30 \mathrm{~min}$ in an aluminium coated pan, followed by cooling to room temperature (Yun et al., 2015; Zhou et al., 2013). For the chemical treatment, $50 \mathrm{mM}$ of 2-bromoethanesulfonate (BES, $\geq 95 \%$; Sigma-Aldrich) was used to inhibit the methanogens (Lins et al., 2015). All, the inoculated bottles were filled with a synthetic gas $\left(\mathrm{H}_{2}: \mathrm{CO}_{2}: \mathrm{CH}_{4} 2: 1: 1.5 \mathrm{v} / \mathrm{v}\right)$ to a final pressure of 1.5 bar. The characteristics of the treated inoculum are shown in Table 1.

\subsubsection{Optimization experiment: effect of the gas compositions}

The inoculum with the most efficient pre-treatment methods (in terms of chemical production and biogas upgrading) from the previous experiment was used in a new batch experiment under four different gas compositions (Table 2). The synthetic gas used in this experiment was a mixture of biogas $\left(40 \% \mathrm{CO}_{2}: 60 \% \mathrm{CH}_{4}\right)$ and pure $(100 \%) \mathrm{H}_{2}$. The difference between the four gas ratios (GR 1-4x ) was based on different ratios between $\mathrm{H}_{2}$ and $\mathrm{CO}_{2}$ (Table 2). For controls, the mixed cultures 
were kept under $100 \% \mathrm{~N}_{2}$ in the headspace. Triplicates were used for each ratio and analysis of variance was performed.

\subsection{Microbial communities analysis} nylon cell strainer filter to remove the animal fibers residues. The samples were centrifuged at $10000 \mathrm{~g}$ for $10 \mathrm{~min}$ at $4^{\circ} \mathrm{C}$ and the supernatant was discarded recovering $\sim 2 \mathrm{~g}$ of pellet. Quality and quantity of the DNA extracted were determined using NanoDrop (ThermoFisher Scientific, Waltham, MA) and Qbit fluorimeter (Life Technologies, Carlsbad, CA). Samples were sent to the Ramaciotti Centre for Genomics (UNSW, Sydney) for sequencing amplified hypervariable V4 region of bacterial and archaeal 16S rRNA genes using universal primers 515F/806R and MiSeq platform (Illumina). Bioinformatics' analyses on raw data were conducted using CLC Workbench software (V.8.0.2) with microbial genomics module plug in (QIAGEN) as previously described by Kougias et al. (2017). Raw reads were deposited in Sequence Read Archive (SRA) database

152 (http://www.ncbi.nlm.nih.gov/sra) under the project number PRJNA388850. The samples' details are given in Table 3 and Table S1 (Supplementary materials).

\section{Table 3 is here}

\subsection{Analytical methods}

Total solid (TS), volatile solid (VS), total chemical oxygen demand (TCOD), total Khjeldhal nitrogen (TKN) and total ammonia $\left(\mathrm{NH}_{4}{ }^{+}-\mathrm{N}\right)$ were measured according to APHA standard methods for the examination of water and wastewater (APHA, 2005). The $\mathrm{pH}$ was measured immediately 
$160 \mathrm{pH}$ meter connected to the Gel pH electrode (pHC3105-8; Radiometer analytical). VFAs were

161 determine using a gas chromatograph (GC) (Shimadzu GC-2010, Kyoto, Japan), which was

162 equipped with a flame ionization detector (FID) and a FFAP fused-silica capillary column (30 $\mathrm{m} \times$

$1630.53 \mathrm{~mm}$ I.D., film thickness $1.0 \mu \mathrm{m}$ ) using nitrogen as a carrier gas.

164 Headspace gas samples were collected using lock gas tight syringes inserted through the rubber

165 stoppers of the bottle reactors. The $\mathrm{CH}_{4}$ and $\mathrm{CO}_{2}$ content in biogas were measured with a gas-

166 chromatograph (Thermoscientific GC-8A, Japan) equipped with an Agilent column (30 m, 20 $\mu \mathrm{m}$

167 OD, $0.32 \mathrm{~mm}$ ID) packed with Porapak Q 80/100 mesh (Supelco, Bellefonte, PA, USA) and with a

168 TCD detector. The $\mathrm{H}_{2}$ gas was determined with a gas-chromatograph (Shimadzu GC-11A, Tokyo-

169 Japan) equipped with a glass column (2 m, $5 \mathrm{~mm}$ OD, $2.6 \mathrm{~mm}$ ID) packed with Porapak Q 80/100

170 mesh (Supelco, Bellefonte, PA, USA) and with a flame ionization detector (FID).

\subsection{Calculations and statistical analyses}

The obtained data were statistically analysed using analysis of variance (ANOVA) with F test.

173 The treatment means were compared using Duncan's multiple range Test at $p<0.05$, using the

174 MSTAT-C statistical computer package (Michigan State University, East Lansing, MI, USA). The

175 figures were made using the OriginLab program (OriginLab Corporation, Northampton,

176 Massachusetts). Mass balance was based on COD balance. Finally, the utilisations of the $\mathrm{CO}_{2}$ and $\mathrm{H}_{2}(\%)$ were calculated using Eq. (1): 


\section{Results and Discussion}

\subsection{The effect of different pre-treatment methods on gas fermentation}

The chemical (50mM BES) treatment of the inoculum had clearly the most significant effect on

The maximum concentration of acetate $(291 \mathrm{mg} / \mathrm{L})$ was achieved by the BES treated inoculum while almost no VFAs were produced by the heat-treated inocula after 4 days incubation (Fig. 1).

subsequently suppresses the activity of methyl-CoM reductase (MCR) enzyme in methanogens, which in turn reduces the methanogenesis rate (Vogels et al., 1988). In accordance with the current study findings, Lins et al. (2015) has reported that $50 \mathrm{mM}$ of BES inhibited completely the VFAs degradation and methanogenesis of a thermophilic sludge-derived inoculum. (Yujiao et al., 2016) also reported that BES addition in a bio-electrochemical system selectively suppressed the growth of methanogens and results in a shift of the dominant activity to acetogenesis.

Interestingly, thermal treatment did not inhibit methanogenesis; this is in contrast to previous studies reported that heating treatment of sludge-derived inoculum at 70 or $90^{\circ} \mathrm{C}$ for $30 \mathrm{~min}$ efficiently inhibited methanogenesis (Table 4) (Zhou et al., 2013; Yun et al., 2015). This could be explained by the presence of heat resistant methanogens (i.e. extreme- and/or hyper-thermophiles) in the sludge-derived inoculum, as reported before (Oh et al., 2003), which were resistant to the applied temperature. The maximum $\mathrm{CO}_{2}$ consumption (95.4\%) was observed with the chemical treatment (BES), which was 45 and $43 \%$ higher than in 70 and $90^{\circ} \mathrm{C}$ treated sludge-derived 
treatment methods. Finally, both thermal treatment fermentations had higher final $\mathrm{pH}$ compared to the BES treatment fermentation due to the lack of organic acids (VFAs) production (Table 4).

\subsection{Evaluation of optimal $\mathrm{H}_{2} / \mathrm{CO}_{2}$ ratio}

\subsubsection{Biogas upgrading}

The maximum biogas upgrading efficiency of $96 \%$ (v/v) was achieved by GR (2x) after 10 days of incubation, which was 19.7, 43.2 and $74.6 \%$ higher than $\mathrm{GR}_{(1 \mathrm{x})}, \mathrm{GR}_{(3 \mathrm{x})}$ and $\mathrm{GR}_{(4 \mathrm{x})}$, respectively (Fig. 2). This was associated with the high uptake of both $\mathrm{CO}_{2}$ and $\mathrm{H}_{2}$ by acetogenic bacteria for this gas ratio with only $2.7 \% \mathrm{CO}_{2}$ and $1.6 \% \mathrm{H}_{2}$ left. Thus, based to the gas quality standard regarding to biogas utilization (Sun et al., 2015), the upgraded biogas can be used as a vehicle fuel or injected into the natural gas grid. Comparing to other biological biogas upgrading methods, the current study is very promising. Beside the significant role in $\mathrm{CO}_{2}$ mitigation, wastes management and biogas upgrading, valuable chemicals (e.g. acetate) that can be used in the chemical and biofuel industry were also produced. Yan and Zheng (2014) found that the concentration of $\mathrm{CH}_{4}$ in upgraded biogas by the microalgae Chlorella sp. could reach $93.7 \%$, while Luo and Angelidaki 218 (2013) and Bassani et al. (2015) reported an average biogas upgrading of 89-96.1\%. Thus the upgrading method of the current study is approximately efficient compared to the previously reported methods and it has the pivotal advantage of high acetate production.

\section{Fig.2 is here}

\subsubsection{Volatile fatty acids production and $\mathrm{pH}$}

Acetate was produced as the main metabolite under all tested gas ratios (Fig. 3). The acetate concentration increased rapidly through the first two days of inoculation for all gas ratios, owing to the rapid consumption of gaseous substrates. The highest acetate concentration (358 HAc mg/L) was achieved in $\mathrm{GR}(4 \mathrm{x})$ with $62 \% \mathrm{H}_{2}$ consumption after 4 days of incubation (Fig. 3 and 4). The acetate produced by $\mathrm{GR}_{(4 \mathrm{x})}$ was significantly higher $(22 \%)$ than that produced by $\mathrm{GR}_{(2 \mathrm{x})}(p<0.05)$, 
228 while there is no significant $(p>0.05)$ difference was observed between GR $(4 \mathrm{x})$ and GR $(3 \mathrm{x})$. The 229 lowest acetate production of $141 \mathrm{mg} / \mathrm{L}$ was observed in $\mathrm{GR}_{(1 \mathrm{x})}$, which was $61 \%$ lower than the 230 acetate produced in GR ${ }_{(4 \mathrm{x})}$. The same behaviour was observed by Groher and Weuster-Botz (2016), 231 who made a comparative study between eight different acetogenic bacteria in stirred-tank reactors 232 with continuous supply of gaseous substrates $\left(20 \% \mathrm{CO}_{2}\right.$ and $\left.80 \% \mathrm{H}_{2}\right)$. In that study, acetate was the 233 main product and the maximum volumetric acetate formation rate was associated with the 234 maximum gas uptake rates. The COD balance showed that acetate accounted for approx. 89 to $93 \%$ 235 of total VFA products for all fermentations (Table 5). Acetate is an important industrial feedstock, 236 which used as a starting material for vinyl acetate and acetic anhydride synthesis (Jang et al., 2012). 237 Moreover, acetate can be converted to valuable metabolites, such as butyrate and ethanol by 238 acetogenic bacteria (Chen et al., 2016). Biological production of acetate by acetogenic bacteria 239 could replace the traditional methods of acetate production, which depends on petrochemicals 240 through methanol carbonylation or acetaldehyde oxidation (Daniell et al., 2012).

241 The microbial biomass formation according to the COD balance accounted 8.6-14.7\% of the $\mathrm{H}_{2}$.

242 The rapid increase in the consumption of the gaseous substrate and the accumulation of acetate 243 significantly reflected on the $\mathrm{pH}$ profiles (Fig. 5). In the experiments with high consumption of 244 gases $\left(\mathrm{GR}_{(2 \mathrm{x})}-\mathrm{GR}_{(4 \mathrm{x})}\right)$ the $\mathrm{pH}$ decreased rapidly between days 2 and 5, and maintained these low 245 levels $(\mathrm{pH}<5.5)$ till the end of the experiment. While in $\mathrm{GR}_{(1 \mathrm{x})}$, no significant $(p>0.05)$ changes on 246 the $\mathrm{pH}$ values was observed throughout the experiment.

\subsection{Microbial Community Composition}

Alpha diversity based on the number of OTUs (Supplementary Fig. S1) showed that the sequencing depth was adequate to cover the microbial species richness. In addition, it was observed 
the different gas compositions. The lowest microbial complexity was observed in the untreated sludge inoculum (BA01), while the highest was observed with samples exposed to gases: BA04, BA06, and BA09. Phylogenetic tree (Fig. 6) and a heat map were used for representing all the microbial communities on the samples and the abundance of the identified OTUs (Fig. 7). Principal coordinate analyses (PCoA) as an assessment tool of the similarities between the microbial communities among samples are depicted in Fig. S2 (Supplementary Information). The samples were well defined into three clusters corresponding to the treatment methods. PCoA also illustrated the significant difference in similarity between the untreated sample BA01 and the samples with different treatment methods, demonstrating the effect of these treatments on the microbial community compositions.

Fig.6 and Fig. 7 are here

\subsubsection{The effect of pre-treatment methods of inoculum on microbial community} compositions

The different treatment methods of the inoculum had a significant effect on the composition of microbial community. There was a shift in the microbial community after exposing the thermally or chemically treated inoculum to fermentation gases $\left(2 \mathrm{H}_{2}: 1 \mathrm{CO}_{2}\right)$ compared to untreated inoculum. Methanobacterium beijingense 1 was the most dominant methanogen with a high relative abundance of $37.9 \%$ after exposing the $90^{\circ} \mathrm{C}$ to gases, while Methanobacterium formicicum 4 was the most dominant $(40.4 \%)$ after exposing the $70^{\circ} \mathrm{C}$ treated inoculum to fermentation gases. Therefore, the high productivity of methane during the first batch experiment (Table 5) was due to the high abundance of these $\mathrm{H}_{2}$-utilizing methanogens, which have the ability to use $\mathrm{H}_{2} / \mathrm{CO}_{2}$ for their growth and methane production (Ma et al., 2005; Battumur et al., 2016). Sulphate reducing bacteria (SRB) were also present in the thermal treated inoculum after fermentation of the gases. SRB can compete with methanogens or grow syntrophically with them depending on the 
availability of sulphate (Muyzer and Stams, 2008). Under sulfate limited conditions, SRB especially Desulfovibrio species can produce acetate, $\mathrm{H}_{2}$ and $\mathrm{CO}_{2}$ in co-occurrence with a hydrogenotrophic methanogens (Bassani et al., 2015), Desulfovibrio oxamicus was one of the primary species that observed in $70^{\circ} \mathrm{C}$ treated inoculum BA05 with a relatively high abundance of $4.02 \%$, which indicates the existence of a potential syntrophic interaction between this species and Methanobacterium formicicum 4. Similarly, Desulfovibrio vulgaris has been observed in $90^{\circ} \mathrm{C}$ treated inoculum BA04 with $1.87 \%$ relative abundance, which also indicates the existence of a potential syntrophic interaction between this species and Methanobacterium beijingense 1 .

Wolinella succinogenes 36 was the second dominant bacterium in the both thermal treated inocula with high relative abundance of $15.74 \%$ and $12 \%$. W. succinogenes is one of the most thoroughly studied fumarate reducing organisms which uses hydrogen and formate as both electron donors and energy sources, while fumarate and $\mathrm{NO}_{3}$ serve as electron acceptors (Stackebrandt et al., 1987). While, a significant lower abundance of methanogens was observed in the chemically treated inoculum that was exposed to fermentation gases compared to the other inoculum treated at $70^{\circ} \mathrm{C}$ and $90^{\circ} \mathrm{C}$. The most dominant bacteria in the chemically treated inoculum were taxonomically assigned as Cloacamonaceae sp. $18(23.08 \%)$ which is a member of the WWE1 (Waste Water of Evry 1) phylum which was frequently reported in anaerobic environments such as AD (Ozbayram et al., 2017). WWE1 appear to be responsible for the early phase of cellulose degradation and/or the fermentation of substrates resulting from cellulose hydrolysis (Limam et al., 2014). The presence of genes coding for several hydrogenases, together with five different ferredoxin oxidoreductase in WWE1 have suggested its involvement in amino acid fermentation (Pelletier et al., 2008). Acetoanaerobium noterae 10 was the second dominant bacteria with a relative abundance of $6.37 \%$. Acetoanaerobium spp acts as homo-acetogenic hydrogen scavenger that has the ability of acetate 
production from $\mathrm{H}_{2}$ and $\mathrm{CO}_{2}$ (Lesnik and Liu, 2014), which explained the higher acetate productivity compared to the thermally treated inocula (Table 4).

\subsubsection{The effect of different gas ratios on the microbial community composition}

The fermentation gas-composition had a significant effect on the microbial community through the second batch compared to the samples without gases (BA10). The most dominant bacterium in the control was related to Thermovirgaceae sp. 8 (10.96\%) followed by Lysinibacillus contaminans 74 (7.95\%), Anaerolinaceae sp. 12 (6.27\%), BA021 sp.11 (6.22\%), SHA-1 sp. 9 (5.51\%),

Cloacamonaceae sp. 18 (5.10\%), SB-1 sp. 14 (4.94\%), and Bacteroidales sp. 16 (2.72\%). It should be noted that the taxonomic assignment of the most highly abundant bacteria was only possible at high taxonomic levels, even by performing a further analysis (i.e. except from the one conducted using CLC Workbench software) using BLASTn search against the NCBI (16S rRNA sequence database). This is particularly interesting as it highlights the novelty of the microbiome residing in gas fermentation systems demonstrating that still remains largely unexplored. For example,

Cloacamonaceae sp. 18 was the most dominant bacteria in all the samples with different gas ratio (BA06 - BA09) with an abundance that ranged from approximately $13 \%$ up to $27 \%$ of the total microbial community in samples BA06 and BA09, respectively. Unfortunately, the low 16S rRNA gene sequence similarity against the genomes deposited in Greengenes and NCBI database do not allow a comparison with other findings in the literature. However, the significant proliferation of this OTU upon BES addition (i.e. almost absent in all the other treatments) indicates a potential key-role during gas fermentation for acetate production. Moreover, it was found that the variation of the samples based on the gas ratio led to a significant difference in microbial structure of the community. Thermovirgaceae sp. 8 (phylum Synergistetes) was the second dominant species in the samples with lower gas ratio BA06 followed by SHA-1sp. 9 and BA021 sp. 11. Members of phylum Synergistetes were previously reported in various anaerobic environments, i.e. anaerobic digesters, 
323 human oral cavity and goat rumen (Hamdi et al., 2015) with a vital role in amino acid degradation

324 (Militon et al., 2015). A. noterae 10, which is an anaerobic bacterium that produces acetate from $\mathrm{H}_{2}$

325 and $\mathrm{CO}_{2}$, was observed in all treated samples exposed to different gas ratios (BA06-BA09). This,

326 which is consistent with the higher acetate production in the samples with treated inocula compared

327 to the control (Fig. 3) (Sleat et al., 1985).

\subsection{Technology potentials for biogas upgrading and biochemicals production}

329 The present study is proposing a new method for biogas upgrading and VFAs production through

330 the mixed culture fermentation of $\mathrm{CO}_{2}$ and $\mathrm{H}_{2}$. However, this research area is still at its infancy and

331 further improvements are necessary to optimise this novel process. These improvements should 332 focus on:

333 - The type of biocatalyst. Using effluents from gas fermentation processes that are already 334 rich in acetogenic bacteria, could lead to higher process productivity.

335 - Omitting the pretreatment step which would reduce the operational costs.

336 - Optimising the gas composition. CO, which is considered as a gaseous pollutant from 337 various industrial activities (Miller et al., 2008), can be used as carbon and energy source 338 instead of $\mathrm{H}_{2}$ through the fermentation process.

339 - Optimising substrate composition. Some Clostridia species have been reported for their 340 ability to reduce volatile fatty acids (VFAs) to their corresponding alcohols (e.g., n-propanol, 341 n-butanol, n-pentanol, n-hexanol, and isobutanol) by using syngas as electron donor (Liu et 342 al., 2014). Therefore, the addition of VFAs to the fermentation media through the gas 343 fermentation processes or the use of VFAs rich waste could lead to the production of higher $344 \quad$ alcohols.

- Improving reactor configuration which is affecting gas liquid mass transfer. As the solubility of $\mathrm{CO}$ and $\mathrm{H}_{2}$ is low (Bredwell et al., 1999), use of gas dispersion systems (e.g. hollow fibre 
membranes), instead of gas addition in the headspace of batch reactors, could increase the liquid gas transfer and thus improve the productivity of the overall process.

349 Therefore, fermentation of $\mathrm{CO}$ and $\mathrm{CO}_{2}$ (in biogas) using fermentative effluent and VFAs rich 350 wastes can significantly contribute in the production of various types of biofuels (biomethane and 351 alcohols).

\section{Conclusions} to valuable chemicals and biomethane was developed. In order to achieve that, chemical treatment with BES was applied to a methanogenic inoculum that completely blocked the activity of methanogens and promoted homoacetogenic acetate production. The homoacetogenic pathway in the chemically treated inoculum was mainly mediated by A. noterae 10 (a hydrogen scavenger) that had the highest relative abundance when a gas ratio of $2 \mathrm{H}_{2}: 1 \mathrm{CO}_{2}$ was applied. These results offer insight into future bio-economy concepts based on integrating existing technologies, such as biogas upgrading and biosynthesis of value-added biofuels.

\section{Acknowledgements}

The authors would like to thank Hector Garcia for the technical support. Illumina sequencing was performed at the Ramaciotti Centre for Genomics (Sydney, Australia). This research was supported financially by The Danish Council for Independent Research (DFF-1335-00142) and Novo Nordisk Foundation (NNF16OC0021568). The first author is also thankful to Ministry of support in the form of a Ph.D. channel mission.

\section{References}


Angelidaki, I., Petersen, S.P., Ahring, B.K., 1990. Effects of lipids on thermophilic anaerobic digestion and reduction of lipid inhibition upon addition of bentonite. Appl. Microbiol. Biotechnol. 33, 469-472. doi:10.1007/BF00176668

APHA, 2005. Standard Methods for the Examination of Water and Wastewater. American Public Health Association, USA.

Bassani, I., Kougias, P.G., Angelidaki, I., 2016. In-situ biogas upgrading in thermophilic granular UASB reactor: key factors affecting the hydrogen mass transfer rate. Bioresour. Technol. 221, 485-491. doi:10.1016/j.biortech.2016.09.083

Bassani, I., Kougias, P.G., Treu, L., Angelidaki, I., 2015. Biogas Upgrading via Hydrogenotrophic Methanogenesis in Two-Stage Continuous Stirred Tank Reactors at Mesophilic and Thermophilic Conditions. Environ. Sci. Technol. 49, 12585-12593. doi:10.1021/acs.est.5b03451

Battumur, U., Yoon, Y.M., Kim, C.H., 2016. Isolation and characterization of a new methanobacterium formicicum KOR-1 from an anaerobic digester using pig slurry. AsianAustralasian J. Anim. Sci. 29, 586-593. doi:10.5713/ajas.15.0507

Chen, Y., Zhang, F., Wang, T., Shen, N., Yu, Z.W., Zeng, R.J., 2016. Hydraulic retention time affects stable acetate production from tofu processing wastewater in extreme-thermophilic (70????C) mixed culture fermentation. Bioresour. Technol. 216, 722-728. doi:10.1016/j.biortech.2016.06.015

Daniell, J., Köpke, M., Simpson, S.D., 2012. Commercial biomass syngas fermentation, Energies. doi:10.3390/en5125372

Fernández-naveira, Á., Veiga, M.C., Kennes, C., 2017. for the production of higher alcohols from syngas / waste gas. J Chem Technol Biotechnol. doi:10.1002/jctb.5194

Groher, A., Weuster-Botz, D., 2016. Comparative reaction engineering analysis of different 
acetogenic bacteria for gas fermentation. J. Biotechnol. 228, 82-94.

doi:10.1016/j.jbiotec.2016.04.032

Hamdi, O., Hania, W. Ben, Postec, A., Bouallagui, H., Hamdi, M., Bonin, P., Ollivier, B., Fardeau, M.L., 2015. Aminobacterium thunnarium sp. Nov., a mesophilic, amino acid-degrading bacterium isolated from an anaerobic sludge digester, pertaining to the phylum Synergistetes. Int. J. Syst. Evol. Microbiol. 65, 609-614. doi:10.1099/ijs.0.068965-0

Kao, C.Y., Chiu, S.Y., Huang, T.T., Dai, L., Hsu, L.K., Lin, C.S., 2012. Ability of a mutant strain of the microalga Chlorella sp. to capture carbon dioxide for biogas upgrading. Appl. Energy 93, 176-183. doi:10.1016/j.apenergy.2011.12.082

Kougias, P.G., Treu, L., Benavente, D.P., Boe, K., Campanaro, S., Angelidaki, I., 2017. Ex-situ biogas upgrading and enhancement in different reactor systems. Bioresour. Technol. 225, 429437. doi:10.1016/j.biortech.2016.11.124

Leonzio, G., 2016. Upgrading of biogas to bio-methane with chemical absorption process: Simulation and environmental impact. J. Clean. Prod. 131, 364-375. doi:10.1016/j.jclepro.2016.05.020

Lesnik, K.L., Liu, H., 2014. Establishing a core microbiome in acetate-fed microbial fuel cells. Appl. Microbiol. Biotechnol. 98, 4187-4196. doi:10.1007/s00253-013-5502-9

Limam, R.D., Chouari, R., Mazéas, L., Wu, T. Di, Li, T., Grossin-Debattista, J., Guerquin-Kern, J.L., Saidi, M., Landoulsi, A., Sghir, A., Bouchez, T., 2014. Members of the uncultured bacterial candidate division WWE1 are implicated in anaerobic digestion of cellulose. Microbiologyopen 3, 157-167. doi:10.1002/mbo3.144

Lins, P., Reitschuler, C., Illmer, P., 2015. Impact of several antibiotics and 2-bromoethanesulfonate on the volatile fatty acid degradation, methanogenesis and community structure during thermophilic anaerobic digestion. Bioresour. Technol. 190, 148-158. 
doi:10.1016/j.biortech.2015.04.070

Luo, G., Angelidaki, I., 2013. Hollow fiber membrane based H2 diffusion for efficient in situ biogas upgrading in an anaerobic reactor. Appl. Microbiol. Biotechnol. 97, 3739-3744. doi:10.1007/s00253-013-4811-3

Luo, G., Angelidaki, I., 2012. Integrated biogas upgrading and hydrogen utilization in an anaerobic reactor containing enriched hydrogenotrophic methanogenic culture. Biotechnol. Bioeng 109, 2729-2736.

Luo, G., Johansson, S., Boe, K., Xie, L., Zhou, Q., Angelidaki, I., 2012. Simultaneous hydrogen utilization and in situ biogas upgrading in an anaerobic reactor. Biotechnol. Bioeng. 109, 1088-1094. doi:10.1002/bit.24360

Ma, K., Liu, X., Dong, X., 2005. Methanobacterium beijingense sp. nov., a novel methanogen isolated from anaerobic digesters. Int. J. Syst. Evol. Microbiol. 55, 325-329. doi:10.1099/ijs.0.63254-0

Micale, C., 2015. Bio-methane generation from biogas upgrading by semi-permeable membranes: An experimental, numerical and economic analysis. Energy Procedia 82, 971-977. doi:10.1016/j.egypro.2015.11.854

Militon, C., Hamdi, O., Michotey, V., Fardeau, M.L., Ollivier, B., Bouallagui, H., Hamdi, M., Bonin, P., 2015. Ecological significance of Synergistetes in the biological treatment of tuna cooking wastewater by an anaerobic sequencing batch reactor. Environ. Sci. Pollut. Res. 22, 18230-18238. doi:10.1007/s11356-015-4973-x

Muyzer, G., Stams, A.J.M., 2008. The ecology and biotechnology of sulphate-reducing bacteria. Nat. Rev. Microbiol. 6, 441-454. doi:10.1038/nrmicro1892

Oh, S.E., Van Ginkel, S., Logan, B.E., 2003. The relative effectiveness of pH control and heat treatment for enhancing biohydrogen gas production. Env. Sci Technol 37, 5186-5190. 
doi:10.1021/es034291y

Ozbayram, E.G., Kleinsteuber, S., Nikolausz, M., Ince, B., Ince, O., 2017. Effect of bioaugmentation by cellulolytic bacteria enriched from sheep rumen on methane production from wheat straw. Anaerobe 46, 122-130. doi:10.1016/j.anaerobe.2017.03.013

Pelletier, E., Kreimeyer, A., Bocs, S., Rouy, Z., Gyapay, G., Chouari, R., Rivière, D., Ganesan, A., Daegelen, P., Sghir, A., Cohen, G.N., Médigue, C., Weissenbach, J., Le Paslier, D., 2008. "Candidatus Cloacamonas acidaminovorans": Genome sequence reconstruction provides a first glimpse of a new bacterial division. J. Bacteriol. 190, 2572-2579. doi:10.1128/JB.01248-07

Ramachandriya, K.D., Kundiyana, D.K., Wilkins, M.R., Terrill, J.B., Atiyeh, H.K., Huhnke, R.L., 2013. Carbon dioxide conversion to fuels and chemicals using a hybrid green process. Appl. Energy 112, 289-299. doi:10.1016/j.apenergy.2013.06.017

Redl, S., Diender, M., Ølshøj, T., Sousa, D.Z., Toftgaard, A., 2017. Exploiting the potential of gas fermentation. Ind. Crops Prod. 106, 21-30.

Rittmann, S.K.-M.R., 2015. A critical assessment of microbiological biogas to biomethane upgrading systems, in: Guebitz, G.M., Bauer, A., Bochmann, G., Gronauer, A., Weiss, S. (Eds.), Biogas Science and Technology. pp. 117-135. doi:10.1007/978-3-319-21993-6

Rotunno, P., Lanzini, A., Leone, P., 2017. Energy and economic analysis of a water scrubbing based biogas upgrading process for biomethane injection into the gas grid or use as transportation fuel. Renew. Energy 102, 417-432. doi:10.1016/j.renene.2016.10.062

Sleat, R., Mah, R.A., Robinson, R., 1985. Bacterium That Forms Acetate from H2 and CO2. Int. J. Syst. Bacteriol. 35, 10-15.

Stackebrandt, E., Fowler, V., Mell, H., Achin, K., 1987. 16S rRNA analysis and the phylogenetic position of Wolinella succinogenes. FEMS Microbiol. Lett. 4, 269-272. doi:http://dx.doi.org/ Sun, Q., Li, H., Yan, J., Liu, L., Yu, Z., Yu, X., 2015. Selection of appropriate biogas upgrading 
technology-a review of biogas cleaning, upgrading and utilisation. Renew. Sustain. Energy Rev. 51, 521-532. doi:10.1016/j.rser.2015.06.029

Vandecasteele, J., 2016. Experimental and modelling study of pure-culture syngas fermentation for biofuels production. Universiteit Gent.

Vogels, G.D., Keltjens, J.T., Van der Drift, C., 1988. Biochemistry of methane production, in: (edn.), Z.A.J.B. (Ed.), Biology of Anaerobic Microorganisms. John Wiley and Sons, New York, N.Y., pp. 707-770.

Xu, H., Wang, K., Holmes, D.E., 2014. Bioelectrochemical removal of carbon dioxide (CO2): An innovative method for biogas upgrading. Bioresour. Technol. 173, 392-398. doi:10.1016/j.biortech.2014.09.127

Yan, C., Muñoz, R., Zhu, L., Wang, Y., 2016. The effects of various LED (light emitting diode) lighting strategies on simultaneous biogas upgrading and biogas slurry nutrient reduction by using of microalgae Chlorella sp. Energy 106, 554-561. doi:10.1016/j.energy.2016.03.033

Yan, C., Zheng, Z., 2014. Performance of mixed LED light wavelengths on biogas upgrade and biogas fluid removal by microalga Chlorella sp. Appl. Energy 113, 1008-1014. doi:10.1016/j.apenergy.2013.07.012

Yujiao, Q., Arnaud, B., Elie, D.L.Q., Fan, L., Pinjing, H., Théodore, B., 2016. Selective inhibition of methanogens using 2-bromoethanesulfonate for improvement of acetate production from $\mathrm{CO}_{2}$ in bioelectrochemical systems. CIESC J. 67, 2033-2040.

Yun, J., Kim, T.G., Cho, K.-S., 2015. Suppression of methanogenesis in hydrogen fermentation by intermittent feeding. J. Environ. Sci. Heal. Part A 4529, 1-10. doi:10.1080/10934529.2015.1074480

Zhou, P., Elbeshbishy, E., Nakhla, G., 2013. Optimization of biological hydrogen production for anaerobic co-digestion of food waste and wastewater biosolids. Bioresour. Technol. 130, 710- 
489

718. doi:10.1016/j.biortech.2012.12.069

490

491

492

493

494

495

496

497

498

499

500

501

502

503

504

505

506

507

508

509

510

511

512 


\section{Table and Figure Captions}

514 Table 1 Characteristics of digested sludge-derived inoculum before and after thermal treatment.

515 Table 2 Composition of different gas ratios used in the batch experiment.

516 Table 3 The samples' information for the 16S rRNA analysis.

517 Table 4 Effect of different treatment methods on gas fermentation.

518 Table 5 COD balance during batch fermentations under different gas ratio.

519 Fig. 1. VFA production profile observed under different treatment methods.

520 Fig. 2. The relative concentration of the $\mathrm{CH}_{4}, \mathrm{CO}_{2}$ and $\mathrm{H}_{2}$ through the upgrading process under

521 different gas ratios: A) $\left.\left.\mathrm{GR}_{(1 \mathrm{x})}\left(\mathrm{H}_{2}: \mathrm{CO}_{2}\right), \mathrm{B}\right) \mathrm{GR}_{(2 \mathrm{x})}\left(2 \mathrm{H}_{2}: \mathrm{CO}_{2}\right), \mathrm{C}\right) \mathrm{GR}_{(3 \mathrm{x})}\left(3 \mathrm{H}_{2}: \mathrm{CO}_{2}\right)$, and D) GR $(4 \mathrm{x})$ $522\left(4 \mathrm{H}_{2}: \mathrm{CO}_{2}\right)$, respectively.

523 Fig. 3. The acetate production under different gas ratios.

524 Fig. 4. $\mathrm{H}_{2}$ consumption profile under different gas ratio.

525 Fig. 5. The $\mathrm{pH}$ fluctuation during the incubation under different gas ratio.

526 Fig.6. Phylogenetic tree of the complete microbial community under different gas ratios and 527 treatment methods.

528 Fig.7. Heat map representing the OTUs with the higher abundance in the samples. The gradient 529 scale above the heat map illustrates the correspondence between the colours and relative abundance. 
Table 1

\begin{tabular}{lllll}
\hline Characteristics & $\mathrm{Unit}$ & $\mathrm{NT}^{*} / \mathrm{BES}$ & $90^{\circ} \mathrm{C}$ & $70^{\circ} \mathrm{C}$ \\
\hline $\mathrm{pH}$ & - & 7.6 & 7.6 & 7.8 \\
$\mathrm{TS}$ & $\mathrm{g} / \mathrm{kg}$ & $47 \pm 0.31$ & $56 \pm 0.06$ & $45 \pm 0.52$ \\
$\mathrm{VS}$ & $\mathrm{g} / \mathrm{kg}$ & $29.3 \pm 0.02$ & $31.7 \pm 0.06$ & $30.5 \pm 0.06$ \\
$\mathrm{NH}_{4}{ }^{+}-\mathrm{N}$ & $\mathrm{g} / \mathrm{kg}$ & $1.6 \pm 0.02$ & $1.3 \pm 0.05$ & $1.4 \pm 0.03$ \\
TKN & $\mathrm{g} / \mathrm{kg}$ & $2.7 \pm 0.03$ & $2.5 \pm 0.03$ & $2.4 \pm 0.06$ \\
Protein & $\mathrm{g} / \mathrm{kg}$ & $16.8 \pm 0.03$ & $15.6 \pm 0.03$ & $15.1 \pm 0.06$ \\
TCOD & $\mathrm{g} / \mathrm{L}$ & $32.1 \pm 0.36$ & $43.0 \pm 1.27$ & $35.0 \pm 0.37$ \\
Acetate & $\mathrm{g} / \mathrm{L}$ & $0.77 \pm 0.03$ & $1.57 \pm 0.08$ & $1.08 \pm 0.11$ \\
Propionate & $\mathrm{g} / \mathrm{L}$ & $0.15 \pm 0.006$ & $0.32 \pm 0.01$ & $0.19 \pm 0.02$ \\
Iso-butyrate & $\mathrm{g} / \mathrm{L}$ & $0.07 \pm 0.002$ & $0.16 \pm 0.002$ & $0.10 \pm 0.004$ \\
Butyrate & $\mathrm{g} / \mathrm{L}$ & $0.06 \pm 0.002$ & $0.22 \pm 0.004$ & $0.11 \pm 0.008$ \\
Iso-valerate & $\mathrm{g} / \mathrm{L}$ & $0.11 \pm 0.003$ & $0.23 \pm 0.001$ & $0.14 \pm 0.006$ \\
Valerate & $\mathrm{g} / \mathrm{L}$ & $0.015 \pm 0.003$ & $0.07 \pm 0.001$ & $0.04 \pm 0.006$ \\
\hline Untreated & & & & \\
\hline
\end{tabular}

"Untreated inoculum 
Table 2

\begin{tabular}{lllll}
\hline Gas ratios & $\left(\mathbf{G R}_{\mathbf{1 x}}\right)$ & $\left(\mathbf{G R}_{\mathbf{2 x}}\right)$ & $\left(\mathbf{G R}_{\mathbf{3 x}}\right)$ & $\left(\mathbf{G R}_{\mathbf{4 x}}\right)$ \\
\hline $\mathrm{H}_{2}: \mathrm{CO}_{2}: \mathrm{CH}_{4}$ & $1: 1: 1.5$ & $2: 1: 1.5$ & $3: 1: 1.5$ & $4: 1: 1.5$ \\
\hline
\end{tabular}


Table 3

\begin{tabular}{ll}
\hline Sample & Information \\
\hline BA01 & The untreated inoculum \\
BA02, BA03 & The thermally treated inoculum at $90^{\circ} \mathrm{C}$ and $70^{\circ} \mathrm{C}$, \\
& respectively \\
BA04, BA05 & The thermally treated inoculum at $90^{\circ} \mathrm{C}$ and $70^{\circ} \mathrm{C}$, \\
& respectively, after exposure to the fermentation gas with a \\
& constant gas ratio $\left(\mathrm{GR}_{(2 \mathrm{x})}\right)$ \\
BA06, BA07, BA08, & The chemically treated inoculum exposed to different gas \\
BA09 & ratio $\mathrm{GR}_{(1 \mathrm{x})}, \mathrm{GR}_{(2 \mathrm{x})}, \mathrm{GR}_{(3 \mathrm{x})}$ and $\mathrm{GR}(4 \mathrm{x})$, respectively \\
BA10 & The control (without fermentation gas) \\
\hline
\end{tabular}


Table 4

\begin{tabular}{llll}
\hline Fermentation parameters & \multicolumn{3}{l}{ Treatment method } \\
\cline { 2 - 4 } & Chemical & Thermal & \\
& $\mathrm{BES}$ & $70^{\circ} \mathrm{C}$ & $90{ }^{\circ} \mathrm{C}$ \\
& 95.4 & 51.5 & 53 \\
Maximum $\mathrm{CO}_{2}$ consumption (\%) & 98.4 & 100 & 100 \\
Maximum $\mathrm{H}_{2}$ consumption (\%) & 5.0 & 6.7 & 6.6 \\
Final pH & 34 & 0 & 0 \\
$\mathrm{CO}_{2}$-to-acetate conversion (\%) & & 100 & 100 \\
\hline $\mathrm{CO}_{2}$-to-methane conversion (\%) & 0 & & \\
\hline
\end{tabular}


Table 5

\begin{tabular}{|c|c|c|c|c|c|c|c|c|}
\hline & \multicolumn{3}{|c|}{ mg-COD $/ L^{*}$} & \multicolumn{5}{|c|}{$\mathrm{mg}-\mathrm{COD}_{\mathrm{f}} / \mathrm{L}^{*}$} \\
\hline & $\mathrm{GR}_{(1 \mathrm{x})}$ & $\mathrm{GR}_{(2 \mathrm{x})}$ & $\mathrm{GR}_{(3 \mathrm{x})}$ & $\mathrm{GR}_{(4 \mathrm{x})}$ & $\mathrm{GR}_{(1 \mathrm{x})}$ & $\mathrm{GR}_{(2 \mathrm{x})}$ & $\mathrm{GR}_{(3 \mathrm{x})}$ & $\mathrm{GR}_{(4 \mathrm{x})}$ \\
\hline Ethanol & 0.5 & 0.4 & 3.1 & 2.3 & 0.4 & 5.7 & 7.7 & 8.5 \\
\hline Propanol & 4.2 & 5.3 & 4.9 & 3.6 & 1.4 & 1.3 & 1.2 & 1.3 \\
\hline Butanol & 1.5 & 1.8 & 1.4 & 1.2 & 0.4 & 0.3 & 0.4 & 0.4 \\
\hline Iso-Amylalcohol & 0.2 & 0.2 & - & - & & - & 0.1 & 0.1 \\
\hline 1-Hexanol & 0.4 & 0.4 & 0.4 & - & 0.2 & 0.2 & 0.2 & 0.2 \\
\hline Acetate & 2.4 & 2.7 & 3.0 & 2.5 & 168.3 & 269.2 & 277.8 & 298.0 \\
\hline Propionate & 1.1 & 1.0 & 0.9 & 0.7 & 12.0 & 7.6 & 8.2 & 7.6 \\
\hline Butyrate & 0.4 & 0.4 & 0.4 & 0.4 & 6.6 & 11.2 & 15.4 & 12.0 \\
\hline Valerate & 0.3 & 0.5 & 0.5 & 0.4 & 1.0 & 1.0 & 1.2 & 0.9 \\
\hline 1-Hexanoate & 0.5 & 0.4 & 0.4 & 0.3 & 0.2 & 0.3 & 0.4 & 0.5 \\
\hline Hydrogen & 408.6 & 788.0 & 1196.6 & 1605.2 & - & 12.6 & 348.8 & 607.1 \\
\hline Overall COD bala & ce $(\%)$ & & & & 93.2 & 87.1 & 86.6 & 85.3 \\
\hline
\end{tabular}




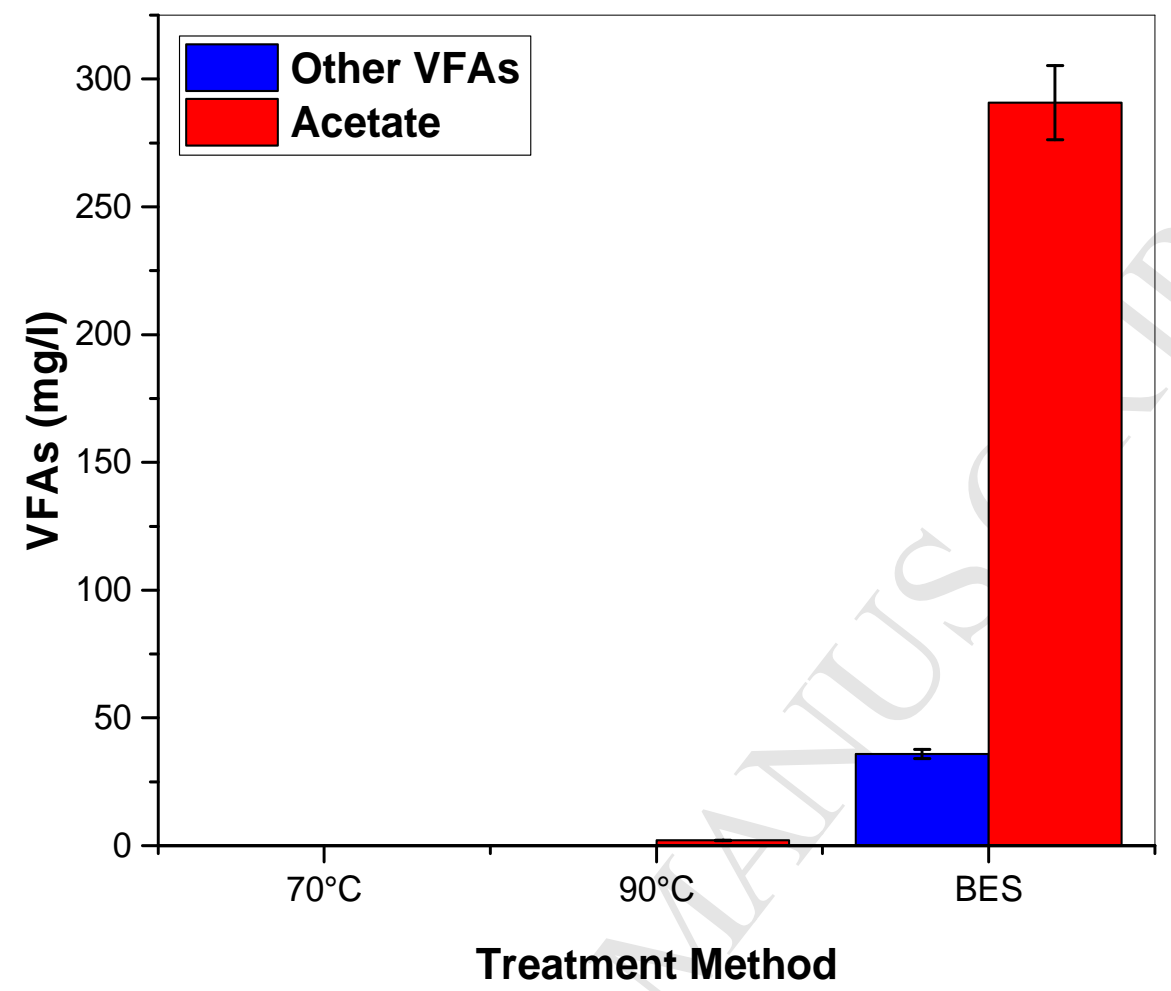

Fig. 1. 

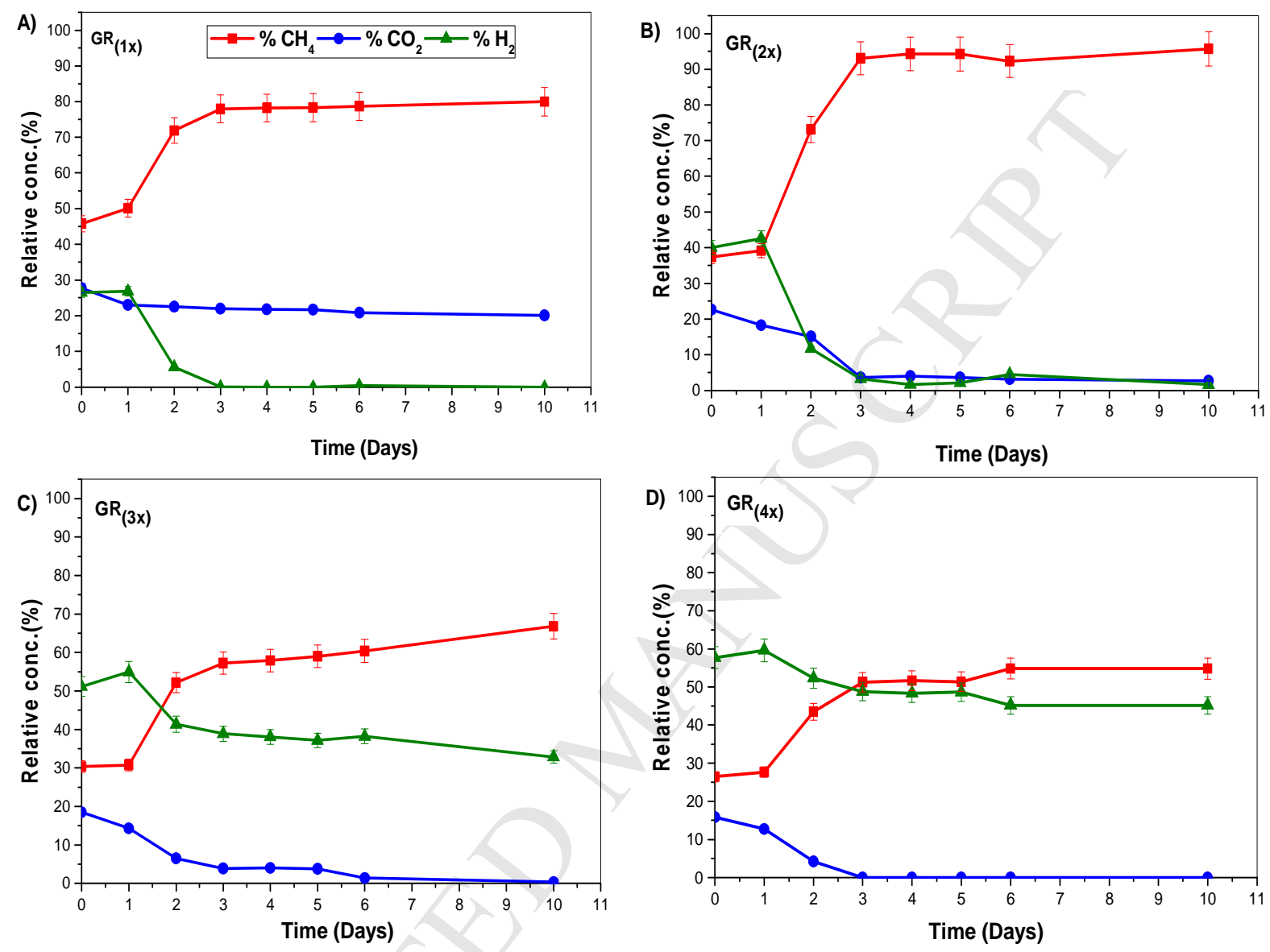

Fig. 2. 


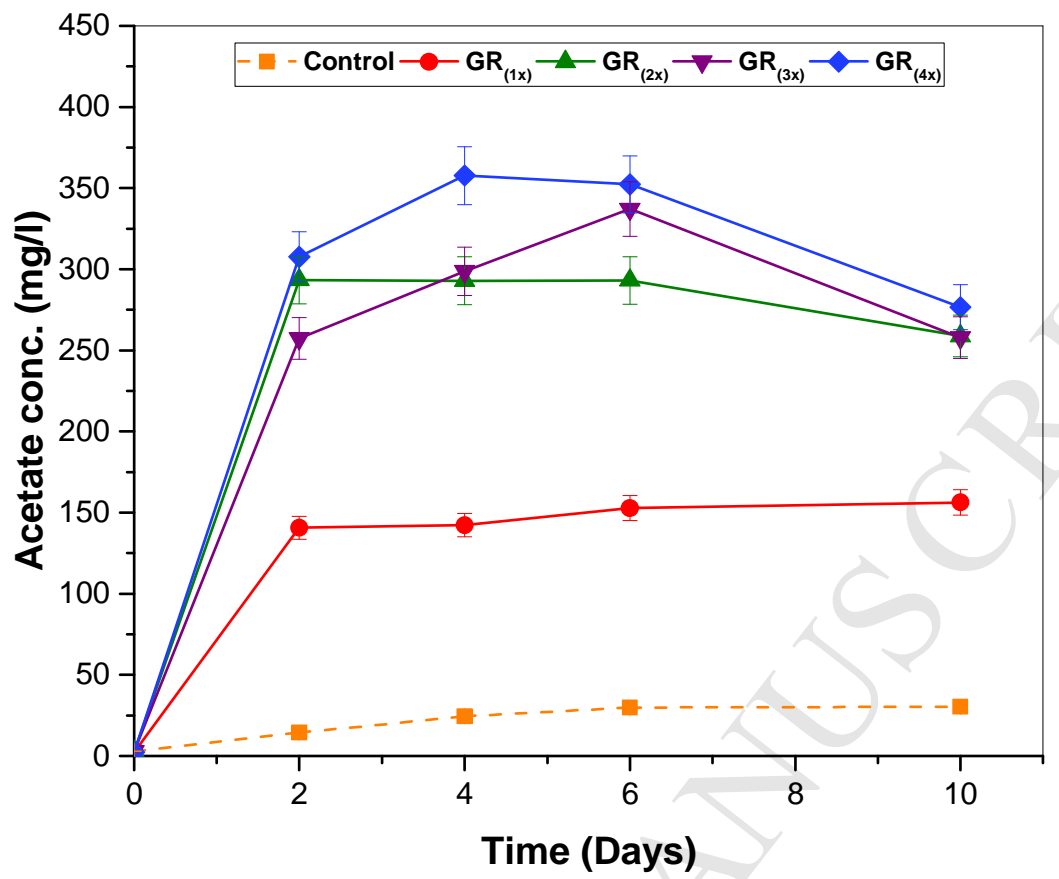

Fig. 3. 


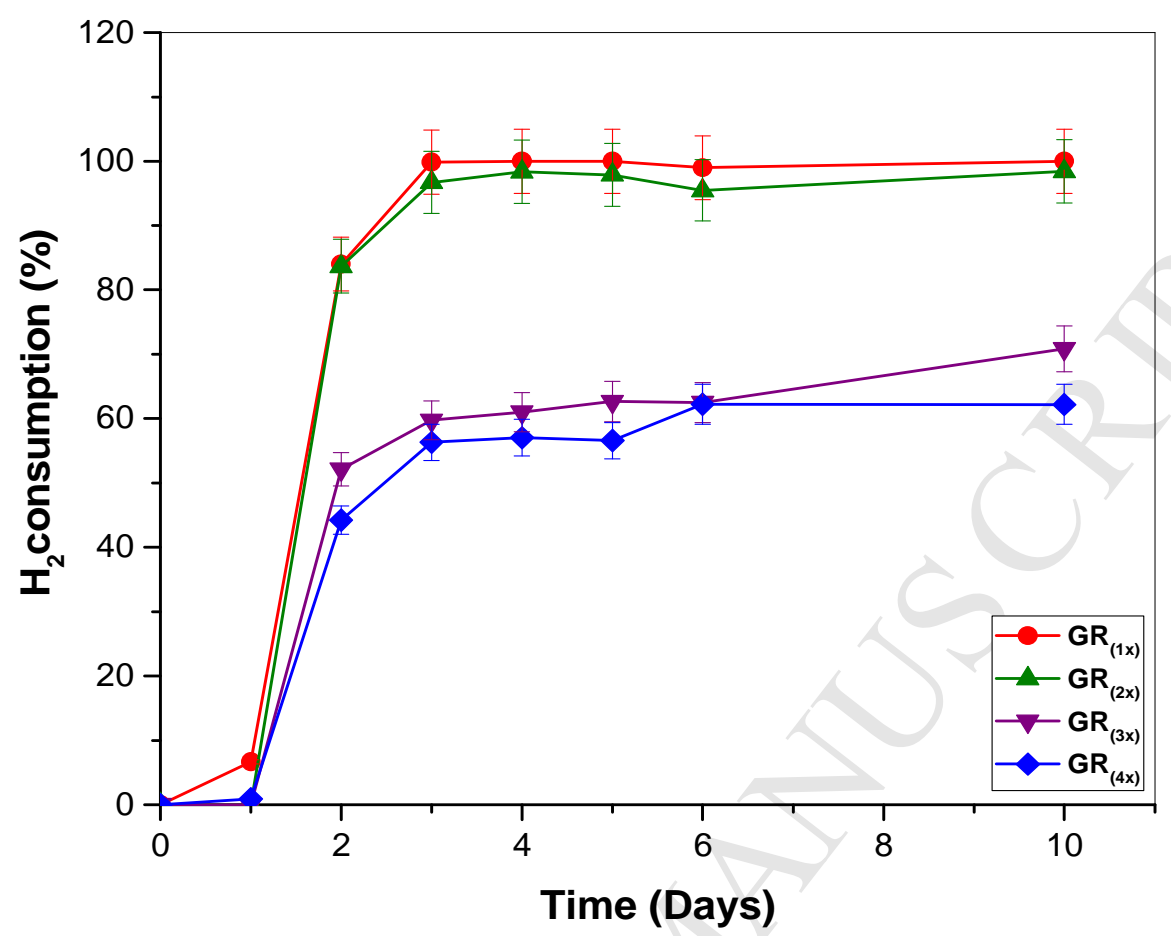

Fig. 4. 


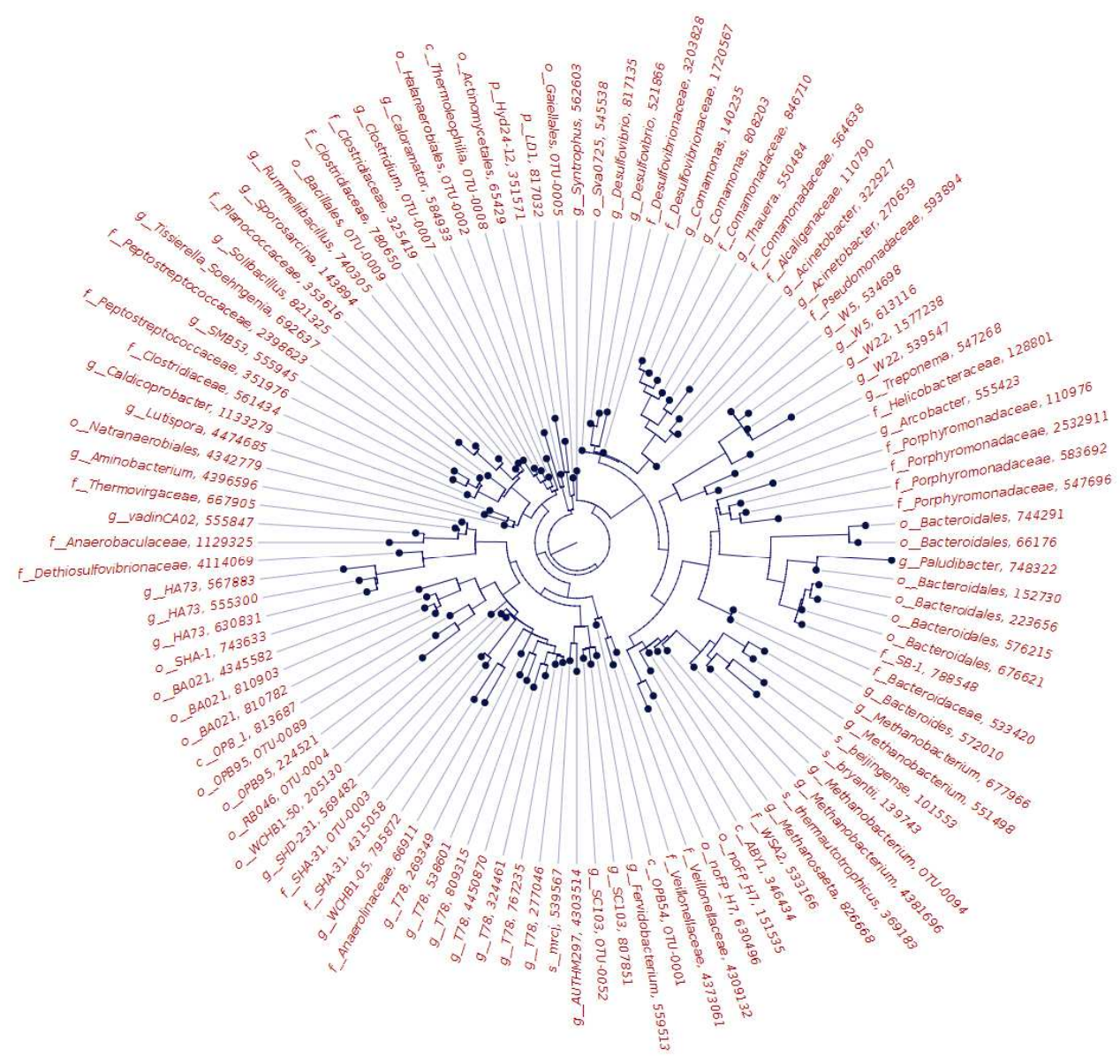

0.600

Fig.6. 


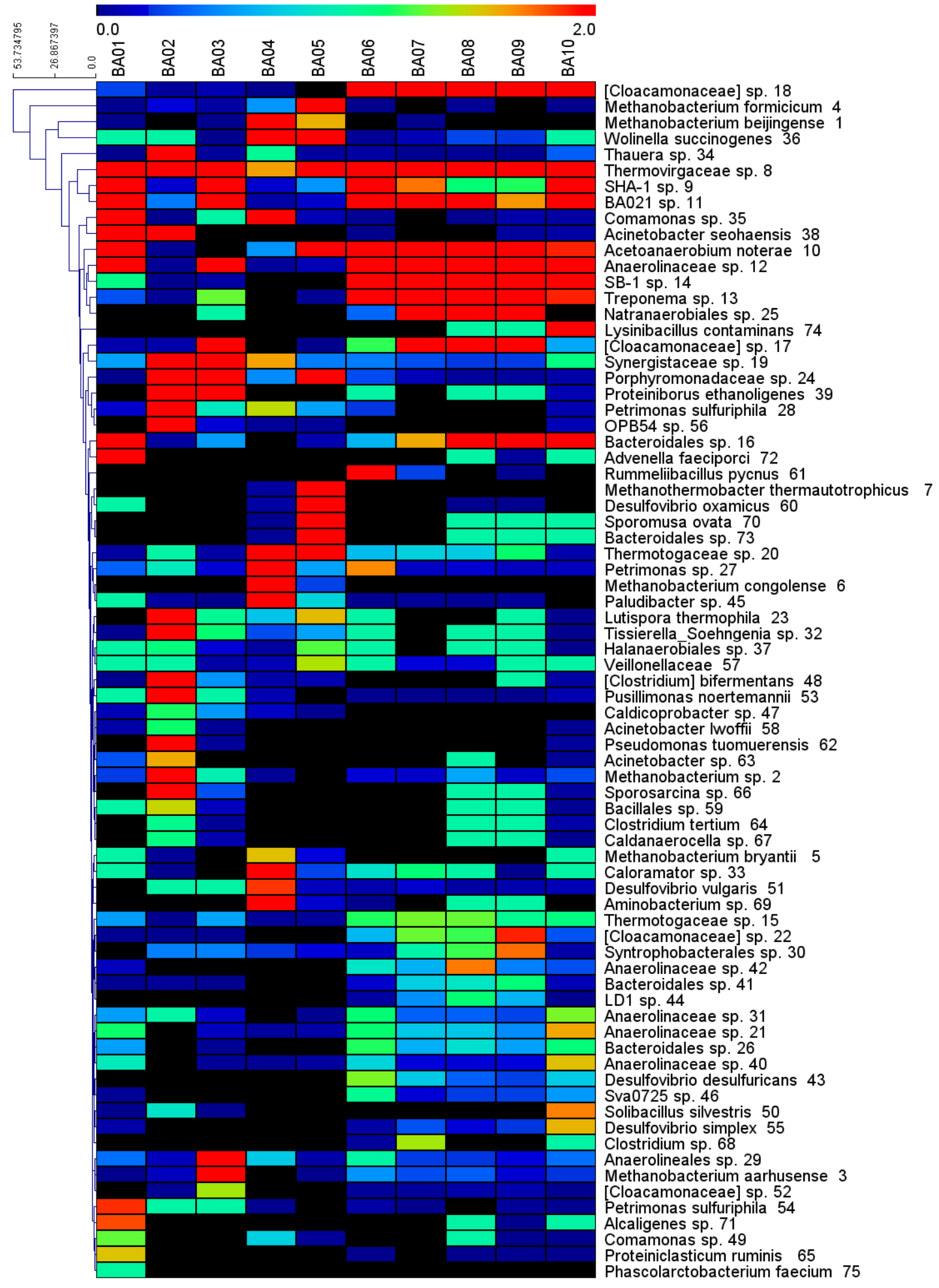

Fig.7. 


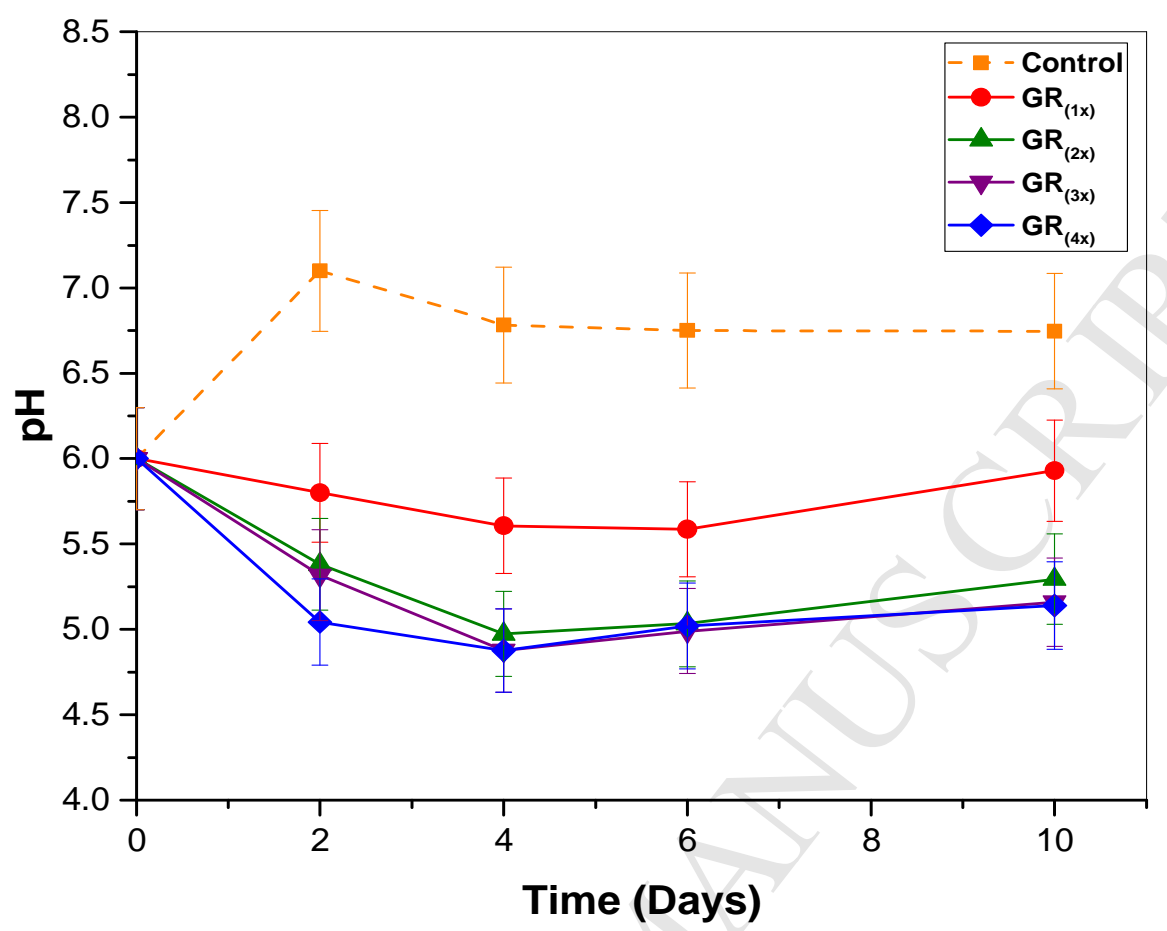

Fig. 5. 


\section{Highlights}

- A novel technique for biological biogas upgrading and $\mathrm{CO}_{2}$ mitigation was developed

- Thermal treatment did not suspend the methanogenic activity of the inoculum

- Chemical treatment enhanced biogas upgrading and acetate production

- Acetoanaerobium noterae 10 was responsible for the high acetate production

- Biomethane with $96 \%$ purity was achieved with $2 \mathrm{H}_{2}: 1 \mathrm{CO}_{2}$ ratio 